\title{
CFD study of airflow and microclimate patterns inside a multispan greenhouse
}

\author{
M. El JAZOUli*, K. LeKouch, A. Wifaya, L. GOURdo, L. BOUIRDEN. \\ Laboratoire de Thermodynamique et Energétique, \\ Faculté des Sciences Université Ibn zohr \\ cité Dakhla BP 8106 Agadir, MORROCO.
}

\begin{abstract}
Understanding and improving greenhouses requires the analysis and modelling of energy and mass exchange phenomena. The mastery of all these physical mechanisms can make it possible to propose technological solutions to control the greenhouse climate. This study presents an analysis and simulation of air flow, temperature and humidity patterns , in 1/2-ha multi-span greenhouse with oblique side walls,covered by insect proof nets. The site is located in the coastal area of southern Morocco. The fundamental calculation of climatic conditions is based on CFD, wich uses the mass, momentum and energy conservation equations. The dynamic influence of the insect screens and tomato crop on airflow movement, was described ,using the concept of the porous medium approach proposed by Darcy and Forchheimer.The coupling of convective and radiative exchanges at the plastic roof cover is considered. A good agreement was observed between the measured and simulated values for inside air temperatures and relative humidity. Insect screens significantly reduced airflow and increased thermal gradients inside the greenhouse. The results clearly showed the heterogeneity of the greenhouse's internal climate, which infects agricultural production in quantity and quality
\end{abstract}

Keywords : Greenhouse; Airflow; CFD; Climatic conditions ; Insect screens;

Received: November 28, 2020. Revised: April 25, 2021. Accepted: May 7, 2021. Published: May 19, 2021.

\section{Introduction}

In south Morocco ,the agricultural production is limited by unfavorable climatic conditions, wich penalize the production in quantity and quality. Moreover, the presence of thrips and aphides are responsible for significant crop damage.Therfore, the use of very fine anti-insect proof nets has been recognized to reduce the need for pesticide application. They act as mechanical barriers to insects but olso reduce the ventilation rate, and raise inside temperature and humidity. [1-6]

The studies for the dynamic characterization of these nets have been based on experimental studies. Computational fluid Dynamics(CFD) have been increasingly used to study greenhouse ventilation. The effects of insect screens on ventilation, have been characterized and numerically modelled, in a tunnel greenhouse.The effect of wind speed on natural ventilation have also been analysed in a greenhouse using a three-dimensional and a two-dimentional CFD simulation respectively. [7-14]

The aim of the present study, was to analyse the distribution of airflow, temperature and humidity fields in new generation of greenhouse recently installed in southern Morocco,in order to find a strucure better adapted to the climatic conditions of our region. The side walls of greenhouse are oblique and covered by only insect nets. The vent opening area is important,in order to preserve adequate climatic conditions. The insect screens are 20/10 for 20 meshes $\mathrm{cm}^{-1}$ along the length, and 10 meshes $\mathrm{cm}^{-1}$ along the width.

We combined an experimental and modelling study. The numerical climate model is based on (CFD) simulation of sensible and latent heat exchanges between the tomato crop and the greenhouse air, with combination of radiative transfers at roof level.The model was first validated by measured data and then used to explore the details of air flow,temperature and humidity distribution. This CFD assisted for exploration of inside climate and allows for a better assessment of the overall climate and plant activity.

\section{Theory}

\section{1. aerodynamic equations:}

The mass, momentum, energie and concentration equations can be represented with the following conservation equation:.

$$
\frac{\partial \Phi}{\partial t}+\frac{\partial}{\partial x_{j}}\left(u_{j} \Phi\right)=\frac{\partial}{\partial x_{j}}\left(\Gamma_{\Phi} \frac{\partial \Phi}{\partial x_{j}}\right)+S_{\Phi}
$$

\subsection{Modeling of flow through insect screens and plants :}

The drag forces induced by insect screens and crop, that correspond to the term $S_{\Phi}$, is included into our CFD study by the porous medium approach given by the Darcy-Forchheimer equation: [14] 
$S_{\Phi}=-\left(\frac{\mu}{K} U+\rho \frac{C_{f}}{\sqrt{K}} U^{2}\right)$

$K=3.44 \times 10^{-9} \alpha^{1.6}$

$C_{f}=\frac{4.30 \times 10^{-2}}{\alpha^{2.13}}$

$\alpha$ is the screen porosity deduced from the thread dimensions. : [17]

$\alpha=\frac{L . W}{(L+d)(W+d)}$

$\mathrm{L}=0.788 \mathrm{~mm}$ and $\mathrm{W}=0.255 \mathrm{~mm}$ are respectively meshes length and width,

$\mathrm{d}=0.28 \mathrm{~mm}$, is the wire diameter.

For the low air speed $\left(0.1-0.5 \mathrm{~m}_{\mathrm{s}} \mathrm{s}^{-1}\right)$, we can considers only the second member of relation (2):

$S_{\Phi}=-\rho \frac{C_{f}}{\sqrt{K}} U^{2}$

The non-linear momentum loss coefficient $C_{f}$ and the permeabilityK can be deduced from equation: [15]

$\frac{C_{f}}{\sqrt{K}}=I_{L A} C_{D}$

2.3 Mesh generation and boundary conditions :

We used Numerical techniques based in finite volumes.The limits of the computational domain include the greenhouse and free space to windward $(10 \mathrm{~m})$, leeward(10m), and on the top $(20 \mathrm{~m})$. (Figure 1)

The grid inside the greenhouse and in the external domain is built of unstructural elements. After several trials with different grid resolutions, the computational

\begin{tabular}{|c|l|l|}
\hline \multicolumn{1}{|c|}{ Parameters } & Mean & S.D \\
\hline Outside temperature Te $\left({ }^{\circ} \mathrm{C}\right)$ & 27.54 & 0.87 \\
Outside relative humidity Rhe $(\%)$ & 46.18 & 2.3 \\
Outside soil temperature Tsi $\left({ }^{\circ} \mathrm{C}\right)$ & 36.7 & 0.78 \\
Wind direction Dv $\left({ }^{\circ}\right)$ & 126.71 & 6.97 \\
Wind speed Uext $\left(\mathrm{m} \mathrm{s}^{-1}\right)$ & 2 & 0.035 \\
Net radiation Rnet $\left(\mathrm{W} \mathrm{m}^{-2}\right)$ & 415.7 & 2.9 \\
& & \\
\hline
\end{tabular}

grid was set to 165600 elements.

The average and standard deviation (S.D) of boundary and outside climatic conditions are summarized in table 1 :

Table1 :Outside climatic conditions (mean and standard deviation)

The measured air velocity and humidity in the windward opening were taken as boundary condition.The measured temperatures were applied to wall boundaries. The outlet boundary conditions were automatically computed to satisfy the continuity conditions.

\subsubsection{Coupling thermal and humidity exchanges between crop canopy and air}

The radiative net flux $R_{n e t}$ reaching each mesh ,is partitioned into convective sensible $Q_{\text {sens }}$ and latent heat fluxes $Q_{\text {lat }}$ : [15]

$$
R_{n e t}-Q_{\text {sen }}-Q_{\text {lat }}=0
$$

The sensible heat flux $Q_{\text {sen }}$ was expressed with the temperature difference between inside air and canopy :

$$
Q_{s e n}=\rho C_{p} I_{A V}\left(\frac{\left(T_{v}-T_{i}\right)}{r_{a}}\right)
$$

The aerodynamic resistance $r_{a}$ was deduced from the air speed:

$$
r_{a}=\frac{\rho C_{p}}{0.288 \lambda}\left(\frac{d_{v} v}{U}\right)^{0.5}
$$

The latent heat fluxes $Q_{l a t}$ was deduced from the humidity difference.

$$
Q_{\text {lat }}=\rho l_{v} l_{e^{1 / 3}} I_{A V}\left(\frac{w_{v}{ }^{*}-w_{i}}{r_{s}+r_{a}}\right)
$$

The Tomato leafstomatal resistance $r_{s}$ was deduced from air temperature and saturation deficit values using Boulard et al.formula:

$$
r_{s}=r_{s \min }\left[1+0.11 \exp \left(0.34\left(6.107 .10^{\frac{7.5 T_{i}}{237.5+T_{i}}}-1629 w_{i}-D_{\max }\right)\right)\right]
$$

The solar radiation received at a height $\mathrm{z}(\mathrm{m})$ is expressed by the following equation: : [16]

$$
\begin{aligned}
& R(z)=R_{g i} \exp \left(-k_{c} I_{L A S}\left(\frac{H-z}{z}\right)\right) \\
& R_{a b s}=R\left(z_{1}\right)-R\left(z_{2}\right)=d R(z)
\end{aligned}
$$

Finally the tomato crop temperature $\left(T_{v}\right)$ can be calculated according to the following equations: [17]

$$
T_{v}=T_{i}+\frac{r_{a}}{\rho C_{p}}\left[\frac{1}{2 I_{L A V}} \frac{d R(z)}{d z}-\rho L_{v} L_{e}^{1 / 3} \frac{\left(w_{i}-w_{a}\right)}{r_{t}}\right]
$$

\section{Materials and methods}

\subsection{The greenhouse}

The studied greenhouse (Fig. 2) is a commercial multispan greenhouse. The dimensions are: $100 \mathrm{~m}$ in length, $50 \mathrm{~m}$ in width, $5 \mathrm{~m}$ in height at the gutter and $7.7 \mathrm{~m}$ at the ridges. The spans and the tomato crop 
rows were oriented North-South. The greenhouse was provided with natural ventilation by means five roof vent openings. The sidewall were oblic and equipped with similar insect screens

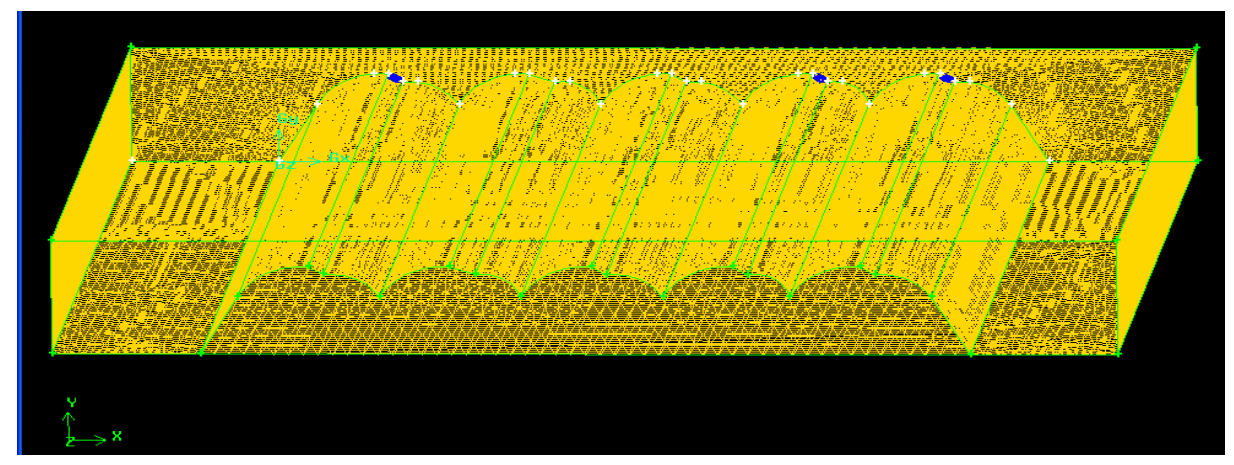

\begin{tabular}{|l|l|l|}
\hline Measured parameters & Sensors name & Locations \\
\hline Inside net radiationR $\mathrm{net}_{\text {net }}$ & Net radiometer Q-7 & $\begin{array}{l}\text { Between the top of the crop and the } \\
\text { roof cover }\end{array}$ \\
\hline $\begin{array}{l}\text { Soil heat flux exchange at ground surface } \\
\mathrm{F}_{\text {net }}\left(\mathrm{W} \mathrm{m} \mathrm{m}^{-2}\right)\end{array}$ & Soil heat flux HFT3 . & $1 \mathrm{~mm}$ below the soil surface \\
\hline $\begin{array}{l}\text { Inside air temperature Ti (K) and relative } \\
\text { humidity RHi (\%) }\end{array}$ & Thermo-hygrometer probes HMP45 AC & $1 \mathrm{~m}$ and $4 \mathrm{~m}$ above soil level . \\
\hline $\begin{array}{l}\text { The temperatures of the inside soil surface } \\
\text { (Tsi) and the outside soil surface (Tse). }\end{array}$ & Thermistors Sensor PT100 & $\begin{array}{l}\text { buried a five centimeters away from } \\
\text { the soil surface . }\end{array}$ \\
\hline $\begin{array}{l}\text { roof cover (Tc) and tomato leaves (Tv) } \\
\text { leaves, }\end{array}$ \\
\hline $\begin{array}{l}\text { The outside wind speed Uext and } \\
\text { direction Dw }\end{array}$ & Thermocouples(Copper-Constantan) \\
\hline Outside radiation $\mathrm{R}_{\mathrm{ge}}$ & Cup anemometer A 100R and Wind vane & $3 \mathrm{~m}$ above the greenhouse ridge \\
\hline
\end{tabular}

Figure 1 : View of the computational grid of the whole study 3D domain for the CFD simulation.

Table2 : Measured parameters, sensors used and locations

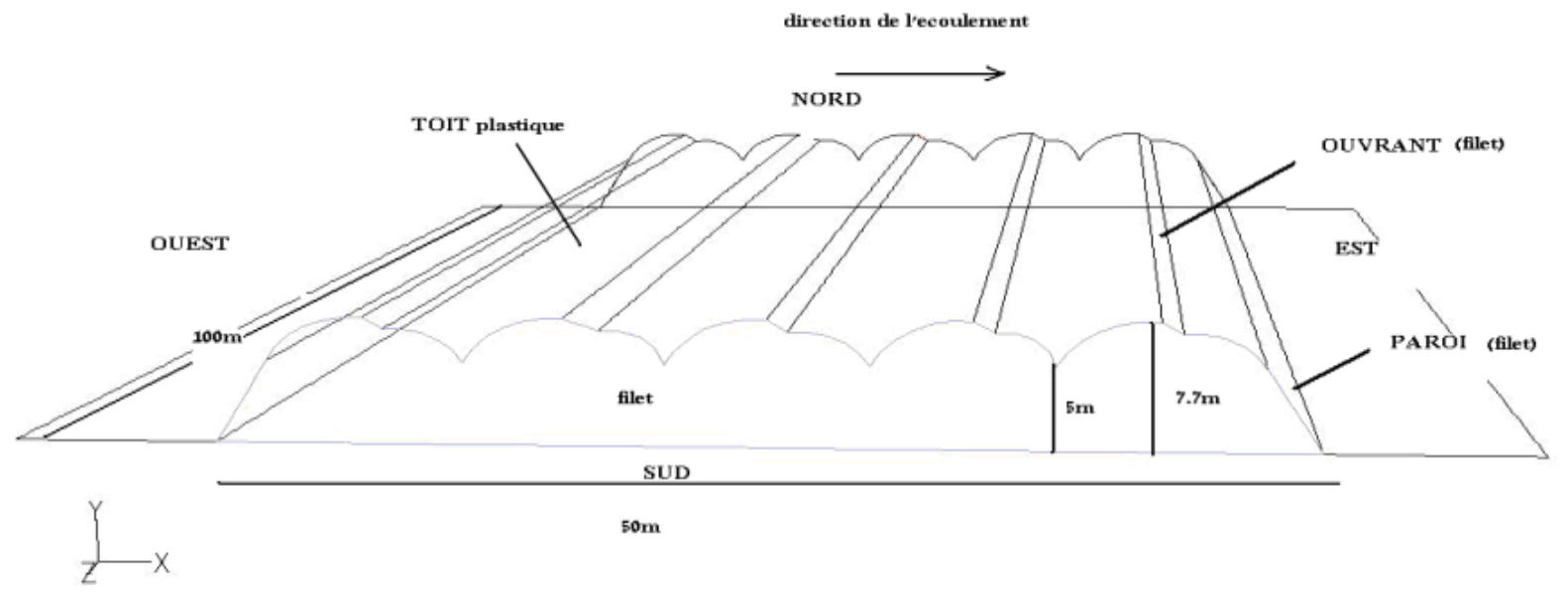

Figure 2: Schematic view of the studied greenhouse, and its ventilation system 
Table2 shows sensors used.All these sensors are connected to two data loggers (Models 23X \&CR850)

\subsection{Experimental conditions}

The greenhouse was occupied by a tomato crop (Calvi), the plant density is 9754 plants/ha the rows are oriented North-South.The leaf area index LAI is 3.The parameters described in Table 2 were used as the boundary conditions and to validate the simulation model.

\section{Results and discussion}

\subsection{Model validation}

Figures 3 and 4, represents the evolution of the simulated and measured profiles of the temperature and humidity at $1 \mathrm{~m}$ above inside soil. We observe that , the evolution of the simulated field follows the measured field but with a $r$ low difference, what allows globally to validate our numeric simulation.

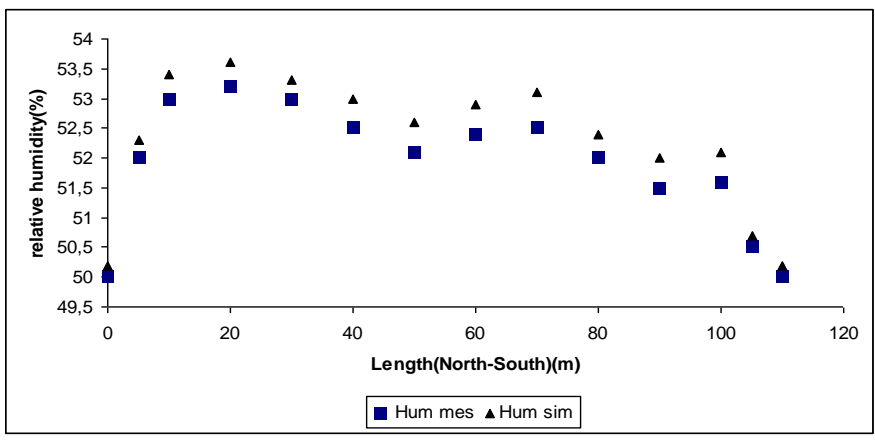

Figure 3: Simulated and measured air temperature profiles at $1 \mathrm{~m}$ above soil according to the length of greenhouse (North-South)

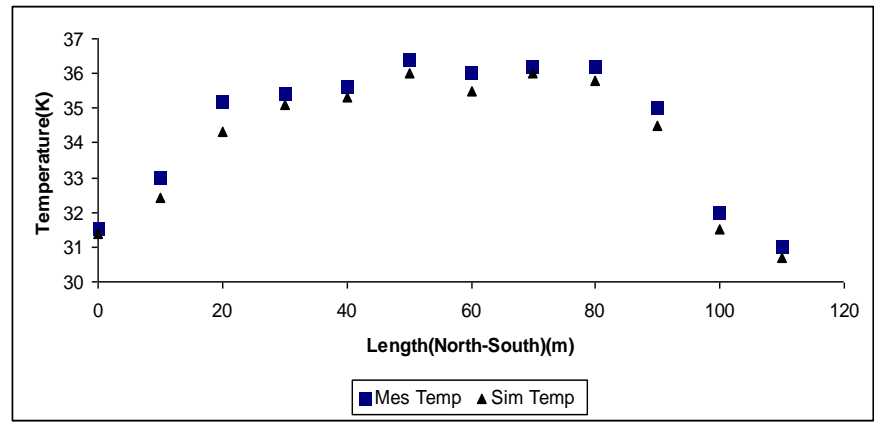

Figure4: simulated and measured relative humidity profiles at $1 \mathrm{~m}$ above according to length of soil

\subsection{Detailed description of inside microclimate :}

Table 3, shows the averages and the standard deviations of the internal climate parameters measured and used to validate the simulation.

\begin{tabular}{|l|l|l|}
\hline \multicolumn{1}{|c|}{ Parameters } & Average & $\begin{array}{l}\text { Standard } \\
\text { Deviation }\end{array}$ \\
\hline Inside temperature $\left({ }^{\circ} \mathrm{C}\right)$ & 35.8 & 0.5 \\
\hline inside relative humidity $(\%)$ & 56,11 & 2,1 \\
\hline Temperature of vegetation $\left({ }^{\circ} \mathrm{C}\right)$ & 30,23 & 0,34 \\
\hline Internal soil Temperature $\left({ }^{\circ} \mathrm{C}\right)$ & 32,12 & 0,8 \\
\hline Internal soil flux $\left(\mathrm{W} / \mathrm{m}^{2}\right)$ & 53 & 1,12 \\
\hline
\end{tabular}

Table 3:average and SD of interne climatic parameters

\subsection{Analyses and discussions of the climatic parameters.}

\subsubsection{Flow field}

figure (5) shows the dynamic field at 4 meters above vegetable cover, we remark that the air flow is characterized by a deceleration speeds of air interiors compared to the external wind. The air interior velocity is about $32 \%$ external velocity, this is due mainly to the presence of the anti-tripe nets on opening ventilation and which contributes partially to air flow resistance.

This figure also shows that there is no direction dominating of the air flow. However, there is the presence of eddies due to interference between opposite directions of air currents from the side and roof opening. A second horizontal cut practised at a height of $1 \mathrm{~m}$ above ground.The (Fig 6) watch that the air velocities on this level are much lower than those observed at high of $4 \mathrm{~m}$. This diminution is due to the presence of a strong density of plants, which causes a reduction of about $90 \%$ external speed.
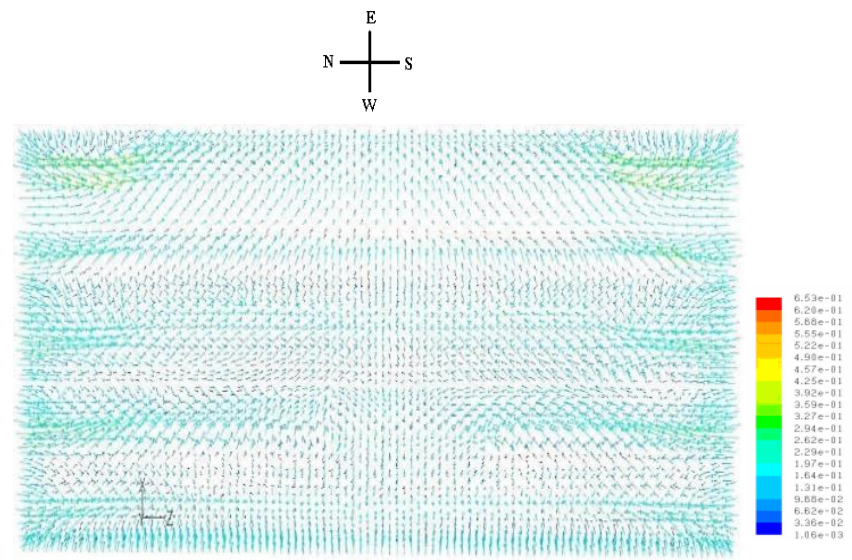

Figure 5: Dynamic field resulting from simulation $(\mathrm{m} / \mathrm{s})$ (horizontal Cut to $4 \mathrm{~m}$ above vegetable cover

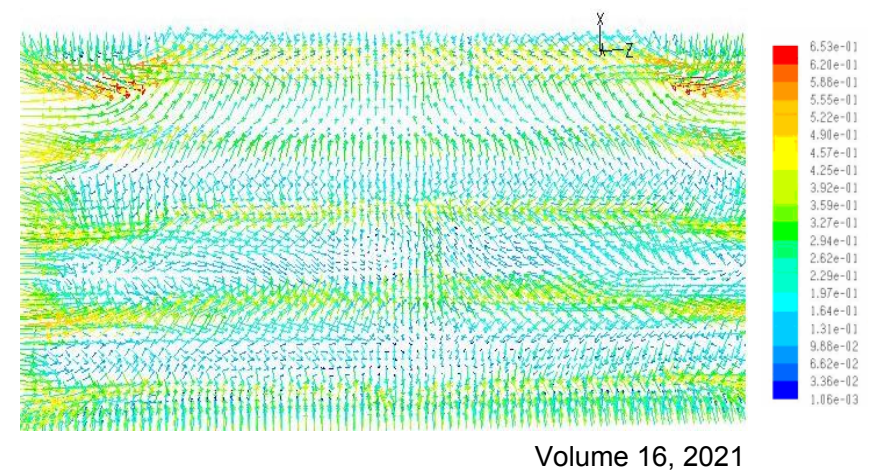


Figure 6: Dynamic field resulting from simulation (Horizontal Cut à $1 \mathrm{~m}$ in vegetable cover.

figure (7) represents a vertical cut applied to the greenhouse center, according to the flow direction. It is noted that a significant jet of fresh air enters by side West opening, and an infiltration of air entering and outgoing through the 5 roof opening. One notices also an outgoing blast air by the Est wall.

This phenomenon is due mainly to the entrance of air which comes from opening zenith roof and walls side

\subsubsection{Temperature Fields}

Figure 8, represents the thermal field at $4 \mathrm{~m}$ on the ground level. It is noticed that the temperature is heterogeneous and varies about $302 \mathrm{~K}$ and $306 \mathrm{~K}$. We notice also the existence of a cold zone near the side walls which are better ventilated.

Figure 9 represents the thermal field at $1 \mathrm{~m}$ on the ground level. It is observed that the temperature is more homogeneous. We can distinguish three distinct zones: Western zone (303K), medium zone (304K) and East zone (306K). This stratification is due to the fact that the Western wall is direct contact with the cold air
Figure 8: Simulated thermal field (horizontal Cut at $4 \mathrm{~m}$ above ground).

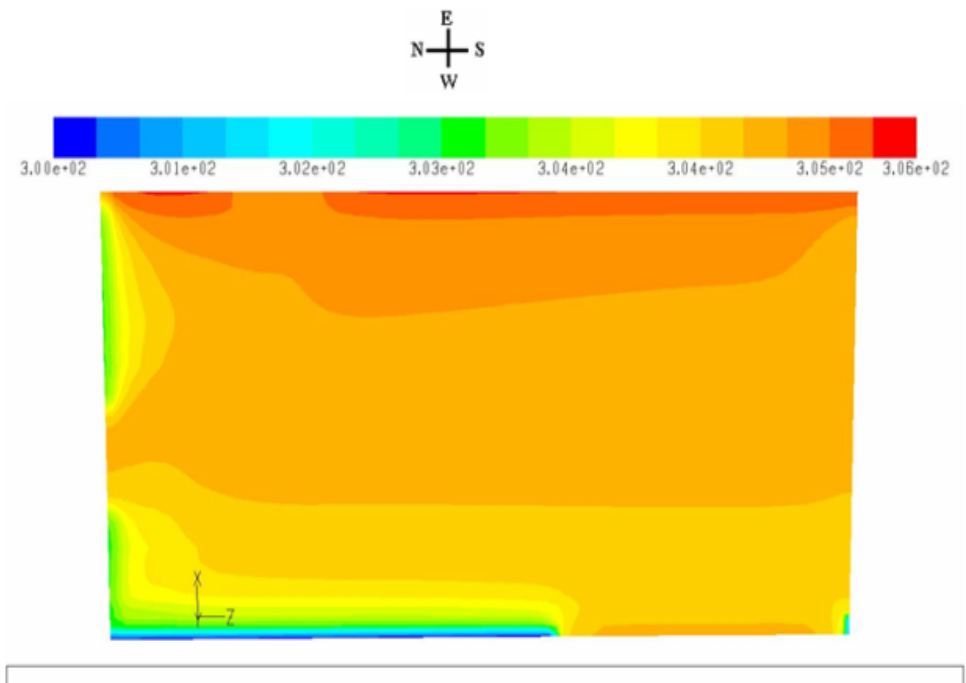

Figure 9: the thermal field at $1 \mathrm{~m}$ on the ground level

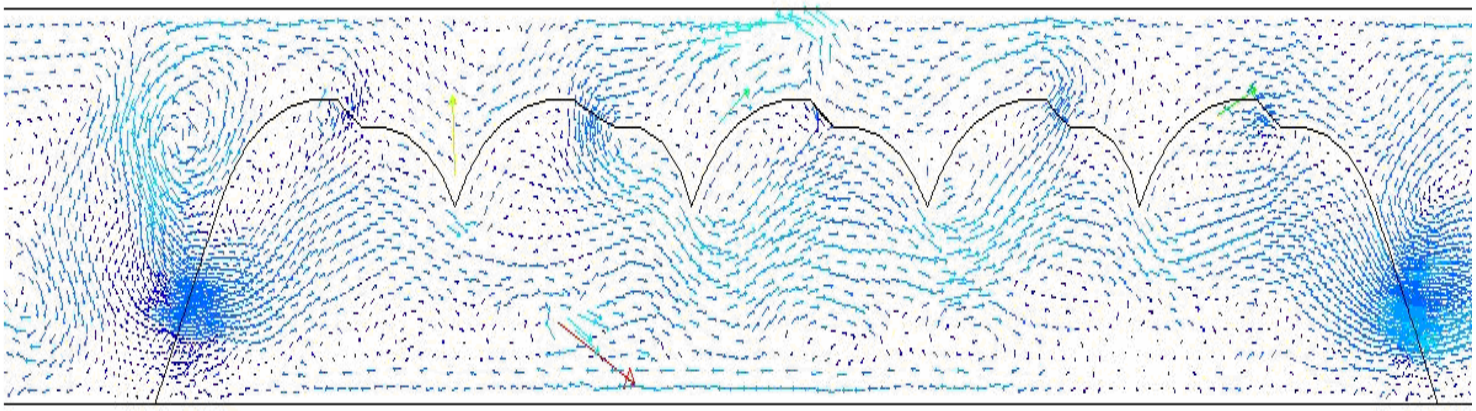

Figure 7:Simulated vertical cross-section of the wind vector field

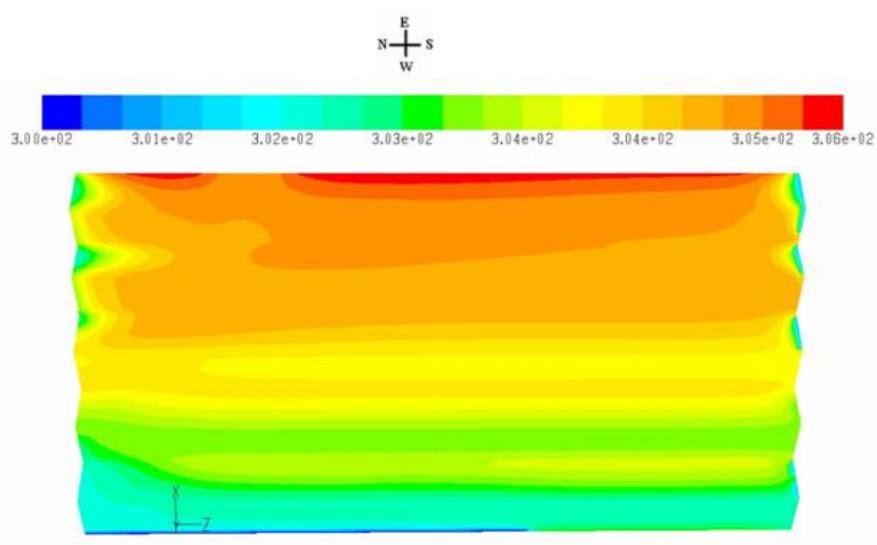

Figure 10, represent vertical cut of the temperature field at $50 \mathrm{~m}$ from the Northern side wall. We notice that in the greenhouse center $(50 \mathrm{~m})$, there is a temperature difference between the Western spans exposed to wind and those of the East located under the wind.We can observe the cold air entries corresponding to Western opening and the heat air outputs from the East side wall 


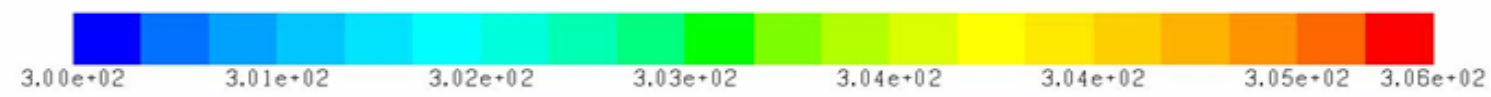

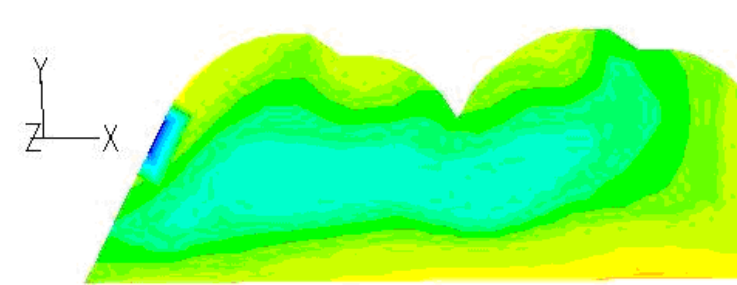

Figures 11,12 respectively represents the relative humidity distribution according to horizontal cuts at 1 and $4 \mathrm{~m}$. It is observed that humidity at $1 \mathrm{~m}$ is more important than $4 \mathrm{~m}$, this is due to plants respiration. On the vegetation level $(1 \mathrm{~m})$ the relative humidity distribution is heterogeneous because it depends on the air entry and exit via the walls. The homogeneity of humidity increases as one moves away from vegetable cover, because the air flow without any obstacle on this level. The relative humidity joined the outside value starting from $4 \mathrm{~m}$ height.

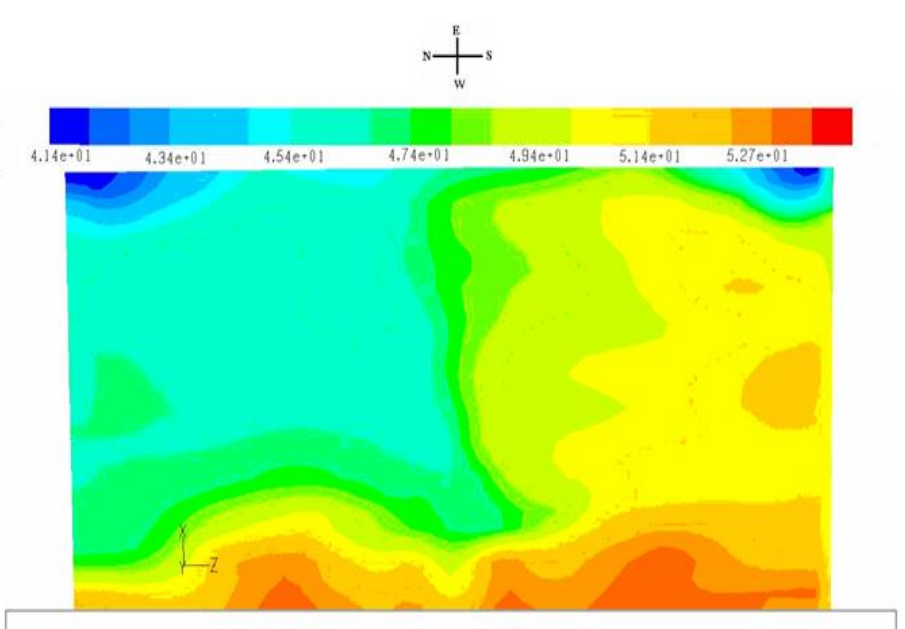

Figure 11: Field of simulated relative humidity. (Horizontal Cut at $4 \mathrm{~m}$ above ground)

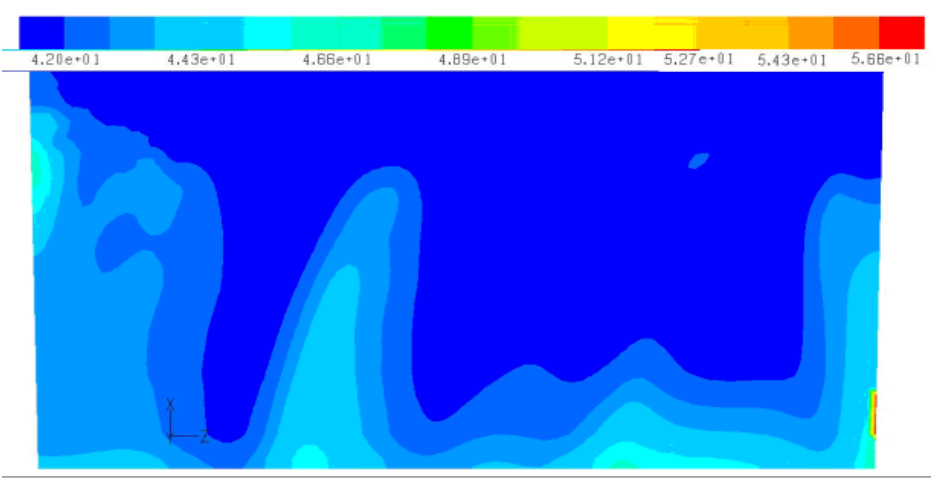

\section{Conclusions}

This work aimed to characterise the internal climate and then numerically simulate the distribution of the internal thermal, hydric and dynamic fields of the greenhouse.

Two approaches were adopted:

-An experimental approach,based on measurements of climatic parameters (temperature, humidity, solar radiation, wind speed and direction...) inside and outside the greenhouse, through which we were able to collect the input mathematical models. This approach also allowed us to characterise the internal climate and to understand the natural aeration in the greenhouse and to refine the knowledge of several mechanisms involved.

- A numerical modelling of the greenhouse microclimate using the fluid mechanics code CFD, which allows the prediction of the velocity, temperature and humidity fields inside the greenhouse after the numerical solution of the Navier-Stockes equations and the heat equation in the considered computational domain. model. We then showed that air flows through insect netting and plant cover can be taken into account through the equivalent porous medium concept developed by Darcy- Forchheimer.

The simulation results clearly showed the heterogeneity of the spatial distribution of the internal climate, despite the high ventilation rate of the greenhouse. This allows us to say that the highest aeration rate is not a priori the best indicator of greenhouse aeration performance.

The analysis of the effect of anti-insect netting showed a strong increase in inside temperature and a significant reduction in wind speed.

One of the most important implications of our study is that farmers can use our work to predict the internal climate changes involved in using the nets or in arranging the crop rows. This allows them to determine 
the best combination for effective protection against insects.

\section{Nomenclature}

$K \quad$ medium permeability $\left(\mathrm{m}^{2}\right)$

$\mathrm{U} \quad$ air speed.$\left(m \cdot s^{-1}\right)$

Cf non-linear momentum loss coefficient

$I_{L A}$ leaf area index

$Q_{\text {sens }}$ convective sensible flux $\left(W . m^{-2}\right)$

$Q_{\text {lat }}$ latent heat fluxes $\left(W . m^{-2}\right)$

$T_{v} \quad$ canopy temperature $(K)$,

$T_{i} \quad$ inside air temperatures $(K)$,

$C_{p}$ specific heat of air at constant

pressure ( $\left.J . K g^{-1} \cdot K^{-1}\right)$,

$I_{A V}$ leaf area index,

$r_{a} \quad$ leaf aerodynamic resistance $\left(s . m^{-1}\right)$

$d_{v} \quad$ characteristic length of the leaf (m);

$w_{v}{ }^{*} \quad$ saturated water content of air $\left(\mathrm{kg} \mathrm{kg}^{-1}\right)$

$w_{i} \quad$ specific humidity of air $\left(\mathrm{kg}_{\mathrm{kg}} \mathrm{kg}^{-1}\right)$

$r_{s} \quad$ tomato leafstomatal resistance $\left(s . m^{-1}\right)$

$R_{g i}$ global radiation inside the greenhouse $\left(W \cdot \mathrm{m}^{-2}\right)$

$R_{g e}$ Outside radiation $\left(W . m^{-2}\right)$

$k_{c}$ extinction coefficient of radiation,

$H$ total height of canopy(m),

$I_{L A S}$ crop stand leaf area index $\left(m^{2} \cdot m^{-2}\right)$

\section{Greek letters}

$\Phi \quad$ studied variable

$\Gamma_{\Phi}$ diffusion coefficient of the quantity $\Phi$

$\varepsilon \quad$ dissipation of the turbulent energy.

$\rho \quad$ air density $\left(\mathrm{kg} . \mathrm{m}^{-3}\right)$

$\mu \quad$ dynamic viscosity $\left(k g . s^{-1} \cdot m^{-1}\right)$

$\lambda \quad$ air thermal conductivity $\left(W \cdot m^{-1} \cdot K^{-1}\right)$

$v$ air viscosity $\left(\mathrm{m}^{2} . \mathrm{s}^{-1}\right)$

$\alpha$ the screen porosity

\section{References}

[1]. Katsoulas et al Effect of vent openings and insect screens on greenhouse ventilation. Biosystems Engineering.(2006).01.001

[2]. Hanafi, A., Bouharroud. R, Mifth \& Amouat. S. (2003a). Performances of two types of insect screens as a physical barrier against B. tabaci and their impact on TYLCV incidence in a greenhouse tomato in the Souss valley of Morocco. In Castané. C \& Hanafi. A (Eds) Integrated control in protected crops, Mediterannean Climate.IOBC wprs Bulletin. Vol. 26 (10) : 39-42.
[3]. Fatnassi, H., Boulard. T., Poncet. C \& Chave. M. (2006). Optimisation of greenhouse insecte screening with Computational Fluid Dynamics. Biosystems Engineering 93, (3), 301-312.

[4]. Montero et al .Computational Fluid Dynamic modelling of night-time energy fluxes in unheated greenhouses. (2005).

[5]. Molina-Aiz et al Using computational fluid dynamics tool to model the internal climate of an Almeri'a-type greenhouse. Acta Horticulturae,654, (2004) 271-278.

[6]. Fatnassi et al) Optimisation of greenhouse insecte screening with Computational Fluid Dynamics. Biosystems Engineering 93, (2006), 301-312..

[7]. Haxaire, R. (1999). Caractérisation et Modélisation des écoulements d'air dans une serre. Thèse de Docteur en Sciences de l'Ingénieur de l'Université de Nice, Sophia Antipolis. 148p.

[8]. Demrati, H., Boulard. T., Bekkaoui. A \& Bouirden. L. (2001). Natural ventilation and microclimatic performance of a large - scale banana greenhouse. J.Agri.Engng Res 80 (3): 291-271.

[9]. Ould Khaoua et al Modélisation de l'aération naturelle et du microclimat des serres en verre de grande portée sous climat tempéré océanique. (2006) Thèse de Doctorat,Université d'Angers France

[10]. Demrati, H., Boulard. T., Bekkaoui. A \& Bouirden. L. (2001). Natural ventilation and microclimatic performance of a large - scale banana greenhouse. J.Agri.Engng Res 80 (3): 291-271.

[11]. Launder and Spalding, The numerical computational of Turbulent flows. Comp. Method App. Mech. Eng. (1974), 3, 269-289.

[12]. Boulard and Wang. Experimental and numerical study on the heterogeneity of crop transpiration in a plastic tunnel. Computers \& Electronics in Agriculture(2002). 34, 173-190.

[13]. Bruse,. Development of a numerical model for the simulation of exchange processes between small scale environmental design and microclimate in urban areas. (1998)Thèse de Doctorat, University of Bochum.

[14]. Miguel et al, ; Airflow through porous screens: from theory to practical considerations. Energy and Building( 1998)28: 63-69.

[15]. Kittas, C. (1980). Contribution théorique et expérimentale à l'étude du bilan d'énergie des serres. Thèse de Doctorat Ingénieur.

[16]. Kaviany, M. (1995). Principles of heat transfer in porous media. Springer. Verlaz, Berlin

Creative Commons Attribution License 4.0 (Attribution 4.0 International, CC BY 4.0)

This article is published under the terms of the Creative Commons Attribution License 4.0

https://creativecommons.org/licenses/by/4.0/deed.en US 